\title{
Acaulospora colossica sp. nov. from an old field in North Carolina and morphological comparisons with similar species, A. laevis and A. koskei
}

\author{
Peggy A. Schultz ${ }^{1}$ \\ James D. Bever \\ Department of Ecology and Evolutionary Biology, \\ University of California-Irvine, Irvine, \\ California 92697-2525
}

\section{Joseph B. Morton}

Division of Plant and Soil Sciences, West Virginia University, Morgantown, West Virginia 26505-6057

\begin{abstract}
A new arbuscular mycorrhizal fungal species, Acaulospora colossica, (Glomales, Acaulosporaceae) is described, and its distribution and seasonality discussed. Spores of $A$. colossica develop from saccules that empty their contents in the developing spores. Spore wall structure consists of 3 layers, all originating from the subtending hyphae. The two inner layers are laminated. The outermost spore wall layer is typically sloughed off before the spores mature. Two inner walls arise sequentially. Both inner walls are comprised of two layers. The outer layer of the innermost wall is beaded. Acaulospora colossica is described from a population in Durham, North Carolina. Its name refers to the relatively large size of the spores. Finally, the morphology of the new species $A$. colossica is compared and contrasted to two closely related species $A$. laevis and $A$. koskei.
\end{abstract}

Key Words: arbuscular mycorrhizal fungus, Glomales, grassland, seasonality, species description

\section{INTRODUCTION}

Large sessile spores were recovered from the rhizosphere of four native plant species in a $75 \mathrm{~m}^{2}$ plot of an old field plant community on the campus of Duke University in Durham, North Carolina. Subsequent trapping of this fungus in greenhouse-grown pot cultures established that it was a new arbuscular mycorrhizal fungal species in the genus Acaulospora. In this paper, we describe this species based on developmentally-defined morphological characters as reported in species of Gigaspora (Bentivenga and Morton 1995), Scutellospora (Franke and Morton 1994, Morton

Accepted for publication March 15, 1999.

${ }^{1}$ Email: pschultz@uci.edu
1995), and Glomus (Morton 1996, Stürmer and Morton 1997).

\section{MATERIALS AND METHODS}

Soils were collected from the rhizosphere of Allium vineale L., Anthoxanthum odoratum L., Plantago lanceolata L., and Panicum sphaerocarpon Ell. growing in the field plot. Soils were mixed 1:1 (v:v) with sterile sand in greenhouse deepots, and seeded with either Sorghum halepense (L.) Pers. or Sorghum vulgare L. separately. In addition, rhizosphere soil was collected to establish trap cultures using the above field plant species as hosts as described by Bever et al (1996). All cultures were grown in a cool season greenhouse (4-21 C) at Duke University for at least $5 \mathrm{mo}$, after which they were dried in situ, the pot contents harvested, bagged, and stored at $4 \mathrm{C}$ for $2 \mathrm{mo}$. Sporulation by the new Acaulospora species was abundant only in the $A$. vineale, $S$. halepense, and $S$. vulgare trap cultures (note $A$. colossica $=$ A. $d 1$ in Bever et al 1996). New healthy spores were extracted from the $A$. vineale culture by sucrose-density gradient centrifugation (Daniels and Skipper 1982), washed, collected and cleaned of all associated organic material and any hyphal fragments present. Washed roots of 12-d-old S. vulgare seedlings were inoculated with spores in the culture room of the International Collection of Arbuscular and VA Mycorrhizal Fungi (INVAM) at West Virginia University (Morton et al 1993). Each inoculated seedling was transplanted into a $4 \times 21 \mathrm{~cm}$ Conetainer(ix) (Stuewe and Sons, Corvallis, Oregon) containing a sterile loamy soil: sand mix (1:2 v:v) adjusted to $\mathrm{pH}$ 6.2. Cultures showed no evidence of sporulation after $5 \mathrm{mo}$, but roots stained by the modified procedure of Koske and Gemma (1989) contained mycorrhizae with lightly staining intraradical hyphae and arbuscules. The contents of selected conetainers were placed in the center of $15-\mathrm{cm}$ pots surrounded with the same growth medium described earlier, seeded with sudangrass [Sorghum sudanense (Piper) Staph.], and cultured further. After 5 mo, sporulation occurred in one pot. Spores of varying stages of maturity and the mycorrhiza from this culture (INVAM NC168) were used to describe the new species, $A$. $\mathrm{Co}^{-}$ lossica.

Spore size was measured with an ocular micrometer and color quantified from a printed color chart (INVAM color chart, available from the authors). The colors on the chart were composed of various percentages of the component colors: cyan, magenta, yellow, and black (C-M-Y-K). A twobranch fiber optic illuminator (color temperature $3400 \mathrm{~K}$ ) was used to illuminate the spores and color chart simultaneously. Spores collected from the field and from all pot cultures were preserved in $0.05 \% \mathrm{NaNO}_{3}$, and vials were 

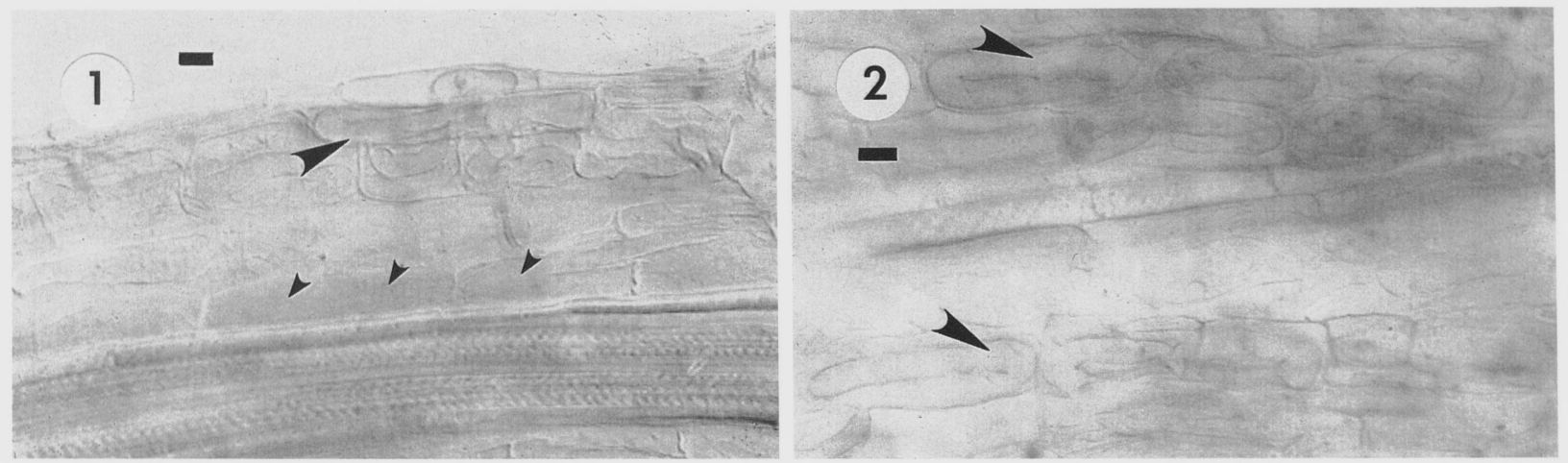

FIGS. 1, 2. Mycorrhizae in roots of sudangrass stained with $0.05 \%$ trypan blue. 1. Faintly stained coiled intraradical hyphae (large arrow) and intracellular arbuscules (small arrows). 2. Faintly stained intraradical hyphae of separate entry points (large arrows). Bars $=5 \mu \mathrm{m}$.

deposited at the Oregon State University (OHC) Herbarium and in the voucher collection of INVAM.

Spores were mounted permanently on glass slides in polyvinyl alcohol-lactic acid-glycerol (PVLG) (Koske and Tessier 1983) and in PVLG with Melzer's agent (1:1 v:v). Spores were broken to varying degrees by applying pressure to the coverslip and examined with a Nikon Optiphot compound microscope equipped with differential interference contrast (DIC) optics. Selected slides also were deposited at the Oregon State University Herbarium and in the voucher collection of INVAM. Color photographs of mycorrhizae and spores can be viewed at the URL http://invam.caf.wvu.edu.

Morphological characters of $A$. colossica spores overlapped enough with those described for A. laevis (Gerdemann and Trappe 1974) to question whether $A$. colossica was a distinct species. In order to make this determination, the holotype specimen of $A$. laevis from Oregon State University was examined. The characteristics of INVAM isolate AU211 (from L. K. Abbott, University of Western Australia, Perth) were consistent with the holotype of $A$. laevis and used as a living reference culture of the species. Spores of A. koskei Błaszkowski also were similar enough in external appearance to both $A$. colossica and $A$. laevis to warrant comparison using reference culture INVAM PL116 (from J. Błaszkowski, Academy of Agriculture, Szczecin, Poland) and WV736 (collected by J. Morton). Spores from active pot cultures of the three species were extracted and mounted as described above and compared microscopically.

\section{TAXONOMIC ANALYSIS}

\section{Acaulospora colossica Schultz, Bever et Morton sp.} nov. Figs. 1-10

Mycorrhizae arbusculares formans. Sacculus hyalinus 240-360 $\mu \mathrm{m}$ in diametro sporogenesem praecedens. Sporae in hypha brevi et laterali, 3.0-6.5 $\mathrm{m}$ longa et 10-17 $\mu \mathrm{m}$ lata, aurantiaco-brunneae aut rubro-fuscae, globosae vel subglobosae, 180-(circiter 270)-380 $\mu \mathrm{m}$ in diametro; stratum sporae e stratis tribus formata, stratum exterius hyaline 1.6-3.2 $\mu \mathrm{m}$ crassum, stratum medium aurantiacum aut aurentiaco-brunneum, lamelliforme, 2.0-5.0 $\mu \mathrm{m}$ crassum, stratum interius lamelliforme, 1.6-5.0 $\mu \mathrm{m}$ crassum; paries flexilis interior stratis duo hyalinis adhaerentibus inaequalibus, exterior $<0.5 \mu \mathrm{m}$ crassum, interior $1.0-2.4 \mu \mathrm{m}$ crassum; paries secundus flexilis interior stratis duo hyalinis adhaerentibus $0.5-0.8 \mu \mathrm{m}$ crassis unaquaeque, exterius "guttulatum", interius laeve; parietes vel strata sporae reagente Melzeri non tincti.

Mycorrhizae of $A$. colossica are patchily distributed in roots of $S$. sudanense. Arbuscules and intraradical hyphae are difficult to discern because they stain lightly in trypan blue (FIGs. 1, 2). Intraradical hyphae often are coiled within cortical cells, ranging from 4$12.5 \mu \mathrm{m}$ diam. Unlike in most Acaulospora species, including $A$. koskei and $A$. laevis no intraradical vesicles are evident at any time.

Spores extracted from 5-mo-old cultures contained spores in all stages of development. Sporiferous saccules form from the ends of external hyphae in soil. Spores rarely develop within mycorrhizal roots. Contents of saccules are pink and saccules collapse once spores are formed. Saccules range from 240-360 $\mu \mathrm{m}$ diam $($ mean $=295 \mu \mathrm{m})$. They attain their full size prior to initiation of spore development. The saccule wall is hyaline, flexible when contents are absent, and 3.2-6.4 $\mu \mathrm{m}$ thick (mean $=3.9 \mu \mathrm{m})$.

Spores arise from the neck of the sporiferous saccule, at a distance of 88-160 $\mu \mathrm{m}($ mean $=127 \mu \mathrm{m})$ from the base of the saccule (FIG. 3). The subtending hypha of the saccule is 33-44 $\mu \mathrm{m}$ diam (mean of 46 $\mu \mathrm{m})$ in the region of attachment to the spore. Spores are smooth, globose to subglobose, 180-380 $\mu \mathrm{m}$ diam $($ mean $=279 \mu \mathrm{m}, \mathrm{n}=190)$, and orange brown (20-80-80-0) to dark red-brown (0-20-60-0) in reflected light. The median spore color is reddish-orange (0-50-60-0). Variation in color from lighter to darker pigmentation correlated directly with an increase in spore size $\left(P<0.01\right.$, and $\left.\mathrm{R}^{2}=0.54, \mathrm{n}=123\right)$.

A "pedicel" or short hyphal branch, 2.5-6.5 $\mu \mathrm{m}$ 

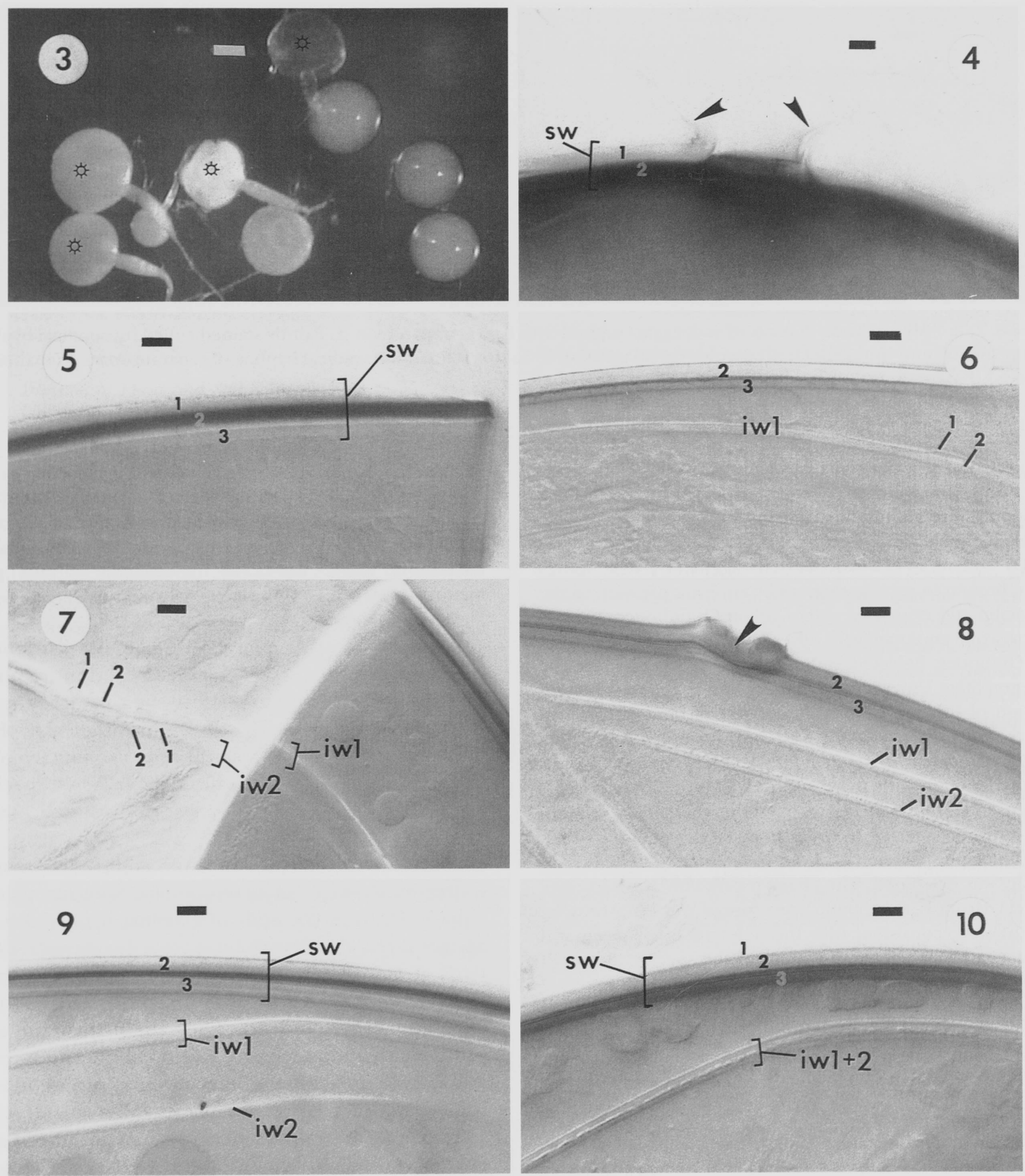

Figs. 3-10. Spores and subcellular structure of Acaulospora colossica. All mounted spores in PVLG and Melzer's reagent $(1: 1 \mathrm{v} / \mathrm{v})$ and photographed with DIC optics. 3. Juvenile and mature spores, some with attached saccules (hollow stars). 4. Juvenile spore in Melzer's reagent with only layers 1 and 2 of the spore wall (sw). Arrows indicate the wall of the neck of the sporiferous saccule continuous with layer 1 of the spore wall. 5. Spore wall (sw) with all three layers $(1,2,3)$ formed. No flexible inner walls are present. 6 . Juvenile spore with only layers 2 and 3 of the spore wall present and the first flexible inner wall (iwl) formed with its two adherent layers $(1,2)$. 7. Mature spore with the two layers $(1,2)$ of each flexible inner wall (iw1, iw2) fully differentiated. 8. Mature spore showing thickening around the pore (arrow) which connected spore contents with that of the neck of the sporiferous saccule (sloughed). 9. Mature spore with layers 2 and 3 of the spore wall slightly separated, and the beading usually present on iw2 dissolved or dispersed. 10. Mature spore wall with all three layers of the spore wall (sw) present and all four layers of the first (iw1) and second (iw2) inner walls adherent. Here the beaded nature of the first layer of iw2 is most evident because it has no room to disperse. Bars: $3=100 \mu \mathrm{m} ; 4-10=5 \mu \mathrm{m}$. 

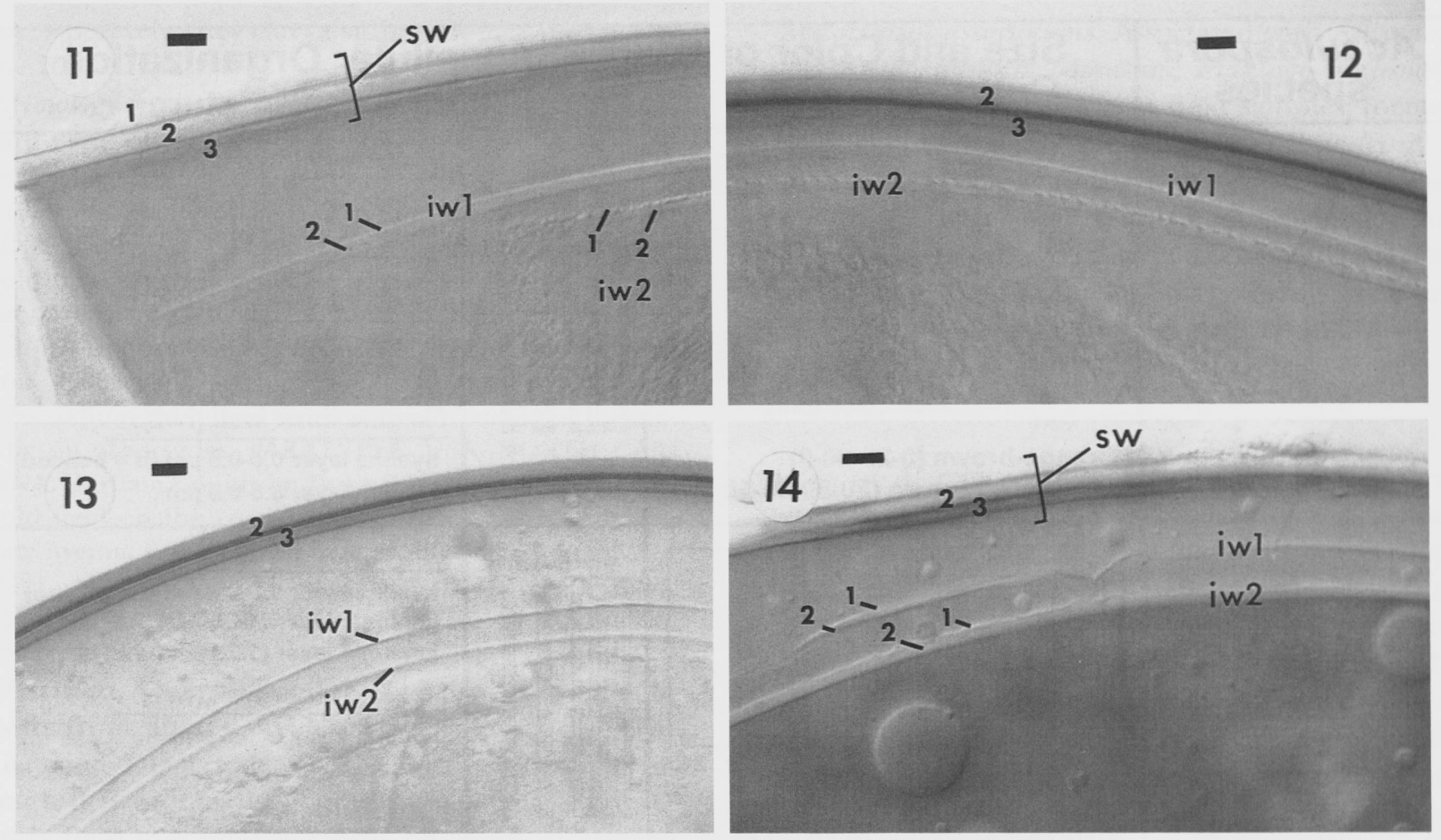

Figs. 11-14. Subcellular structure of spores of other Acaulospora species with similar appearance under a stereomicroscope. 11. Broken spore of A. laevis in PVLG, showing all three layers $(1,2,3)$ of the spore wall (sw) and the two layers (1, 2) of the two flexible inner walls (iw1, iw2). 12. Broken spore of A. laevis in Melzer's reagent, with the first layer of the spore wall absent, and showing the absence of any reaction in layers of the two flexible inner walls (iw1, iw2). 13. Broken spore of $A$. koskei in PVLG, showing the spore wall with only two $(2,3)$ of its three layers present. Both layers of the two flexible inner walls (iw1, iw2) are tightly adherent and each appear as monolayers. The beaded surface of iw2 also has disappeared (within 5 days of mounting). 14. Broken spore of A. koskei in Melzer's reagent, showing the dextrinoid staining reaction of layer 3 of the spore wall (sw) and layer 2 of the second flexible inner wall (iw2). Here, both layers $(1,2)$ of each flexible inner wall are discernible. Bars $=5 \mu \mathrm{m}$.

long, connects the spore and hypha beneath the saccule (FIG. 4). The pedicel wall is a thinner continuation of layers of the spore wall (see below), 1.6-3.2 $\mu \mathrm{m}$ thick at the spore and thinning to $<0.5 \mu \mathrm{m}$ where it is attached the the saccule hypha. The pedicel usually breaks close to the base of the spore, revealing the cicatrix. The cicatrix remaining after saccule detachment is $10-17 \mu \mathrm{m}$ wide (mean $=14.6$ $\mu \mathrm{m})$.

Each spore differentiates a spore wall as it expands with three phenotypically discrete layers (FIG. 5). Once the spore wall is completely differentiated and the spore has ceased expansion, a separate flexible wall (iw1) with two adherent layers originates from the spore cytoplasm (FIG. 6). After it has completed differentiation, a second flexible wall (iw2) with two adherent layers forms (FIG. 7). This linear sequence of spore wall and two inner walls parallels patterns of differentiation in other Acaulospora species (Stürmer and Morton unpubl) as well as Scutellospora species (Franke and Morton 1994, Morton 1995).
The outer layer of the spore wall (1) (FIG. 5) is an extension of the wall of the saccule neck and encloses the spore as it is formed. It is hyaline, 1.6-3.2 $\mu \mathrm{m}$ thick when intact in juvenile spores. As spores mature this outer layer degrades and sloughs off the spore. It is rarely present on mature spores that have detached from the parent saccule. The remaining two layers (2 and 3) (FIG. 5) are synthesized from layer 1 after the spore has been formed. These inner two layers are "laminate" in that they consist of fine adherent sublayers most apparent at the broken edges of crushed spores. These two inner layers completely enclose the spore contents without a morphologically distinct occlusion. Their continuity is evident when they are observed beneath the raised edges of the former pore (FIG. 8). Layer 1 is orange (0-60-100-10) to orange-brown (0-40-50-10) in color and 2.0-4.8 $\mu \mathrm{m}$ thick $($ mean $=3.25 \mu \mathrm{m})$. Layer 2 appears darker orange-brown in PVLG containing Melzer's reagent. It adheres to layer 1 when layer 1 is present. The inner laminate layer, layer 3 , often is adherent to lam- 


\begin{tabular}{|c|c|c|c|}
\hline $\begin{array}{l}\text { Acaulospora } \\
\text { species }\end{array}$ & $\begin{array}{l}\text { Size and Color of } \\
\text { Cultured Spores }\end{array}$ & $\begin{array}{r}\text { Subc } \\
\text { Murograpl }\end{array}$ & $\begin{array}{l}\text { ellular Organization } \\
\text { Structures }\end{array}$ \\
\hline $\begin{array}{l}\text { A. colossica } \\
\text { Schultz, Bever \& } \\
\text { Morton } \\
\text { (this paper) }\end{array}$ & 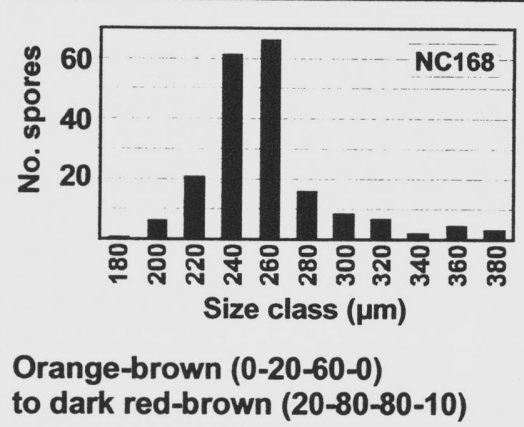 & 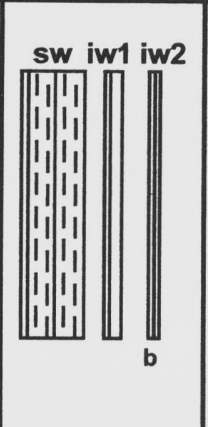 & 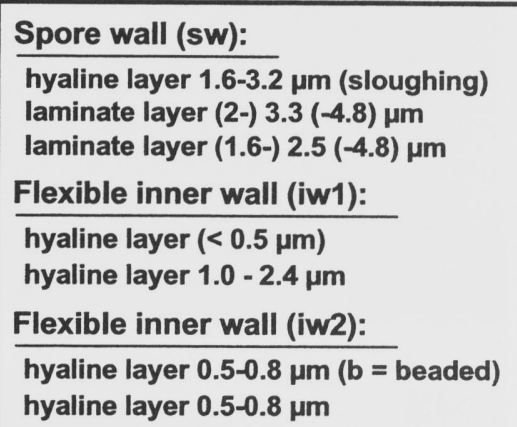 \\
\hline $\begin{array}{l}\text { A. laevis } \\
\text { Gerdemann \& } \\
\text { Trappe (1974) } \\
\text { Reported size: } \\
\text { 120-280 } \mu \mathrm{m} \\
\text { Reported color: } \\
\text { "honey-colored" } \\
\text { to reddish-brown }\end{array}$ & 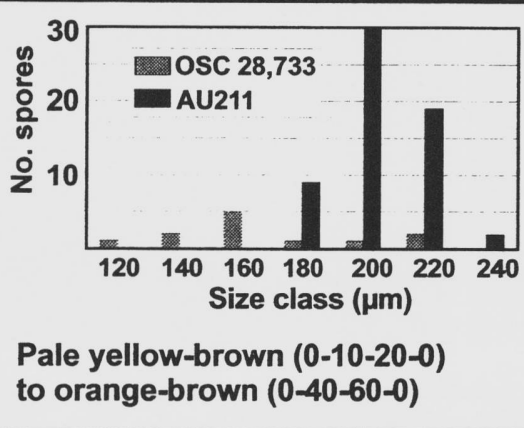 & 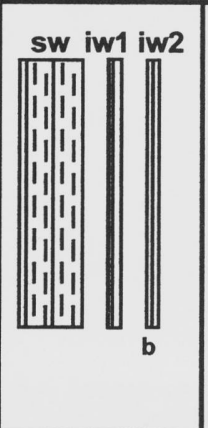 & $\begin{array}{l}\text { Spore wall (sw): } \\
\text { hyaline layer 1.2-2.0 } \mu \mathrm{m} \text { (sloughing) } \\
\text { laminate layer }(1.6-) 1.9(-2.8) \mu \mathrm{m} \\
\text { laminate layer (1.2-) } 1.4(-1.6) \mu \mathrm{m} \\
\text { Flexible inner wall (iw1): } \\
\text { hyaline layer }(<0.5 \mu \mathrm{m}) \\
\text { hyaline layer } 1.0-1.8 \mu \mathrm{m} \\
\text { Flexible inner wall (iw2): } \\
\text { hyaline layer } 0.5-0.8 \mu \mathrm{m}(\mathrm{b}=\text { beaded) } \\
\text { hyaline layer } 0.5-1.0 \mu \mathrm{m}\end{array}$ \\
\hline $\begin{array}{l}\text { Reported size: } \\
(80-) 183(-340) \mu m \\
\text { Reported color: } \\
\text { Orange-white to } \\
\text { reddish-orange }\end{array}$ & 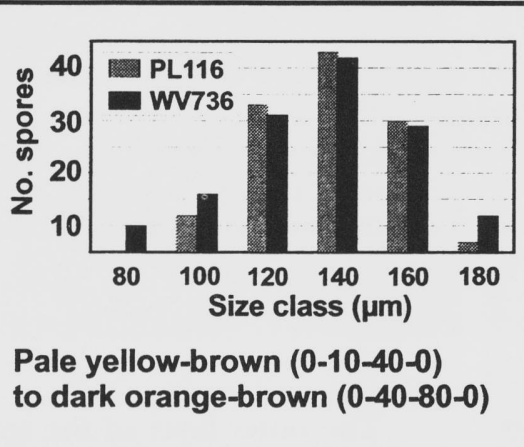 & 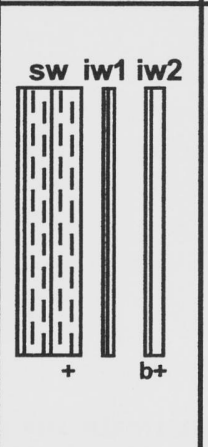 & $\begin{array}{l}\text { Spore wall (sw): } \\
\text { hyaline layer } 1.3-2.2 \mu \mathrm{m} \text { (sloughing) } \\
\text { laminate layer }(1.3-) 1.9(-2.8) \mu \mathrm{m} \\
\text { laminate layer }(1.2-) 1.4(-1.6) \mu \mathrm{m} \\
\text { Flexible inner wall (iw1): } \\
\text { hyaline layer }(<0.5 \mu \mathrm{m}) \\
\text { hyaline layer } 0.5-1.0 \mu \mathrm{m} \\
\text { Flexible inner wall (iw2): } \\
\text { hyaline layer } 0.5-1.0 \mu \mathrm{m}(\mathrm{b}=\text { beaded) } \\
\text { hyaline layer } 0.5-1.1 \mu \mathrm{m}(+=\text { dextri- } \\
\text { noid reaction in Melzer's reagent) }\end{array}$ \\
\hline
\end{tabular}

FIG. 15. A comparison of all properties of spores of $A$. colossica and species of similar appearance under a stereomicroscope, A. laevis and A. koskei.

inate layer 2, but sometimes separates with applied pressure, especially in older spores. Layer 3 is light brownish yellow $(0-10-40-0$ to $0-10-60-0)$ in transmitted light, $1.6-4.8 \mu \mathrm{m}$ thick (mean $=2.5 \mu \mathrm{m}$ ) and does not produce a discernible reaction in Melzer's reagent. Layer 3 often is hard to see with brightfield optics because it is concolorous with layer 2 .

The first flexible inner wall (iw1) consists of two hyaline layers that often are adherent (FIG. 9), but occasionally separate slightly in some broken spores (FIG. 6). The outer layer (1) is very thin, never exceeding $0.5 \mu \mathrm{m}$. The inner layer (2) is thicker, 1.0$2.4 \mu \mathrm{m}($ mean $=1.8 \mu \mathrm{m})($ FIG. 6$)$. Neither layer of iw1 produces a noticeable reaction in Melzer's reagent.
The second flexible inner wall (iw2) consists of two hyaline layers of common origin, but which together originate independent of iw1 and the spore wall. These two layers are adherent, flexible and of near equal thickness $(0.5-0.8 \mu \mathrm{m})$ (FIGS. $8-10)$. The surface of the outer layer is covered with numerous surface granular excrescences (or "beads") that often separate with applied pressure in PVLG, but which become fixed in formalin (Morton 1986) or in $\mathrm{NaNO}_{3}$ (Figs. 7, 8, 10). After storage in PVLG mountants, these beads often dissolve and disappear, so that iw2 appears smooth (FIG. 9). The inner layer of iw2 rarely reacts in Melzer's reagent, but when it does the color reaction is never darker than a very pale pink (0-20-10-0). Even though the two inner walls de- 
velop separately, they can be adherent in some spores (FIG. 10).

Etymology. Latin, colossica, referring to the atypically large size of the spores relative to that of spores of most other species in the genus Acaulospora.

Collections examined. HOLOTYPE. USA. NORTH CAROLINA: Durham County on Duke University campus, from an old field on the corner of Alexander Drive and University Avenue; J.D. Bever from INVAM culture NC168, 16 Feb 1994. Deposition at Oregon State University (OSC assession \#69035) consists of whole spores preserved in $0.05 \%$ sodium azide and broken spores mounted permanently on glass slides. PARATYPES. USA. NORTH CAROLINA: Durham County on Duke University campus, from an old field on the corner of Alexander Drive and University Avenue P. A. Schultz, 18 Nov 1994, \#B23-4 (INVAM V1442), \#D2-54 (INVAM V1417); J. D. Bever, 1/2/94, \#JB42, \#JB44, \#JBAL4, NC168 (S3075), 27 Apr 1996, (S3302), 24 Sep 1996.

Distribution and habitat. This species is only known from an old field on the campus of Duke University, Durham County, North Carolina, although it is widely distributed in this field. Soil $\mathrm{pH}$ in this field averaged 5.2. Soil phosphorus ranged from 7.6 to $48.9 \mathrm{Kg} \mathrm{ha}^{-1}$, and averaged $17.8 \mathrm{~kg} \mathrm{ha}^{-1}$. The average percent organic matter at the sampling sites was 4.2 and the range varied from 1.07 to 14.13 . The plant community at this site is diverse, without having a clear cut dominant species, and is phenologically divided into a warm season and a cool season association (Fowler and Antonovics 1981, Moloney 1988). Spore densities at sampled sites also varied greatly, with some sites containing as many as 51 spores of $A$. colosssica in $50 \mathrm{~cm}^{3}$ of soil while others had none (Schultz 1996).

Notes. Four lines of evidence suggest that $A$. colossica occurring in this field is active during cool months. First, spores were most abundant in the spring (mean 31.8 in $50 \mathrm{~mL}$ of soil). Spore numbers declined in the summer (mean 16.4) and fall (mean 5.6) and then increased in winter (mean 13.3) $(P<$ 0.04. $\left.\mathrm{F}_{3,14}=3.78\right)$. Fresh saccules were only observed on spores collected in the spring (Schultz 1996). Second, A. colossica sporulated sparsely, if at all, in repeated trap cultures grown in a warm season greenhouse (15-30 C) under natural light, but sporulated profusely, often being the dominant fungal species, in similar trap cultures grown in a cool greenhouse (4-25 C) with similar lighting (Bever et al 1996, Schultz 1996). Third, A. colossica presence was correlated in the field with plants that grew throughout the year or only in the cool season (Schultz 1996). Finally, A colossica sporulated most abundantly in trap cultures with $A$. vineale as host, which is a plant species whose growth is favored in the cool season (Bever et al 1996).
Mycorrhizal associations. Associated with Allium vineale, Anthoxanthum odoratum, Plantago lanceolata, and Panicum sphaerocarpon in field samples; formed arbuscular mycorrhizae on $A$. vineale, $S$. vulgare, $S$. halapense, and $S$. sudanense in a greenhouse-grown pot culture. Both colonization and sporulation are slow to develop, often requiring culture duration longer than five months and often requiring reseeding of the culture and additional growth cycles.

\section{DISCUSSION}

Spores of $A$. colossica are amongst the largest of all species in Acaulospora, comparable only to A. foveata Janos \& Trappe and A. tuberculata Janos \& Trappe (Janos and Trappe 1982, Schenck et al 1984). Saccule morphology also is distinctive in its large size, which correlates with spore size $(P<0.001, \mathrm{n}=12$, $\left.\mathrm{R}^{2}=0.72\right)$. Only $A$. colossica (INVAM NC168) and $A$. tuberculata (INVAM VZ103E) have been successfully cultured in this group of species; for both these isolates induction of sporulation required two or more successive propagation cycles over a 9-12 mo period with sudangrass as host.

Spores of $A$. colossica mostly closely resemble those of A. laevis Gerd. \& Trappe and A. koskei Błaszkowski under a dissecting microscope. All three species overlap in the color range from pale yellow-brown to orange brown and are shiny due to lack of any surface ornamentation or adherent organic matter. Some spores of $A$. colossica are uniquely red to red-brown, especially those collected from field soils, but they represent only a fraction of sample populations examined to date.

Subcellular structure and the phenotypic properties of each layer in the spore wall and two inner flexible walls are identical in spores of $A$. colossica and A. laevis (FIGS. 11, 12). The only divergent feature in the spore wall of $A$. colossica is that all layers are thicker. We consider this difference to be linked to the much larger spore size (and possibly longer developmental period for differentiation of layers in the spore wall) of $A$. colossica.

Subcellular structure of $A$. koskei spores differs from that of $A$. colossica and A. laevis (FIGs. 13, 14). Layers of the spore wall are similarly organized (three layers, with the inner two layers laminate), but the innermost laminate layer (L3) of $A$. koskei stains orange-brown (0-60-40-0) to red-brown $(0-60-50-10)$ in Melzer's reagent (FIG. 13) and it is nonreactive in spores of A. colossica or A. laevis. The first flexible inner wall (iw1) of $A$. koskei also consists of two thin layers, but they often are so adherent as to appear as a single layer and they are collectively thinner than iw1 of either A. colossica and A. koskei (FIG. 14). The 
innermost layer of the second inner wall (iw2) in $A$. koskei spores stains light red-purple (20-60-20-0) in Melzer's reagent, whereas it is nonreactive or stains at most a very pale pink reaction $(0-10-10-0)$ in spores of $A$. colossica or A. laevis. Both differential reactions in Melzer's reagent clearly distance $A$. koskei from the other two species.

Spore size of A. colossica, A. laevis, and A. koskei isolates were compared from pot cultures grown under similar environmental conditions to reduce nonheritable variation (FIG. 15). Distribution of size classes was greatest in samples of $A$. colossica NC168, overlapping only with spores of A. laevis AU211. Spores of A. laevis from a living culture were larger than those sampled from the holotype, but together they bracketed the size range reported in the protologue (Gerdemann and Trappe 1974). Acaulospora koskei accessions from Poland and the United States produced spores with almost identical size distributions, and they did not overlap with those of $A$. colossica. The protologue reports a much broader size distribution that overlaps with A. colossica (Błaszkowski 1995), the reasons for which we cannot determine from existing data or literature.

The above comparisons indicate that the only morphological features distinguishing $A$. colossica from A. laevis are larger size (with concomitant thickness of spore wall layers) and a greater range in color toward dark red-brown. This pattern fits the developmental model explaining morphological variation in Glomales (Morton et al 1995), in which species-level differences reside solely in properties of the spore wall in all genera. The same pattern has been documented thus far in the genera Gigaspora (Bentivenga and Morton 1995), Scutellospora (Franke and Morton 1994, Morton 1995), and Glomus (Morton 1996, Stürmer and Morton 1997). Developmental patterns also indicate that inner wall organization and structure are more highly conserved than that in the spore wall, so that these structures group species into higher taxa (Morton et al 1995). Based on these patterns of morphological divergence, we are confident that $A$. colossica is a new species but the discovery of additional geographic isolates are needed to affirm the species-level grouping criteria defined in this paper.

\section{ACKNOWLEDGMENTS}

We are grateful to S. P. Bentivenga and W. Wheeler for discussions and assistance and to Dr. W. Culberson for translation of the Latin diagnosis. We acknowledge the support of USDA grants 92-3701-7461 and 94-37101-0354
(JDB) and NSF grants DEB-9615941 (JDB) and DIR9015519 (JBM).

\section{LITERATURE CITED}

Bentivenga SP, Morton JB. 1995. A monograph of the genus Gigaspora incorporating developmental patterns of morphological characters. Mycologia 87: $720-732$.

Bever JD, Morton JB, Antonovics J, Schultz PA. 1996. Hostdependent sporulation and species diversity of arbuscular mycorrhizal fungi in a mown grassland. J Ecol 84: 71-82.

Błaszkowski J. 1995. Acaulospora koskei, a new species in Glomales from Poland. Mycol Res 99:237-240.

Daniels BA, Skipper HD. 1982. Methods for the recovery and quantitative estimation of propagules from soil. In: Schenk NC, ed. Methods and principles of mycorrhizal research. St. Paul, Minnesota: Amer. Phytopathol. Soc. p 29-35.

Fowler NC, Antonovics J. 1981. Competition and co-existence in a North Carolina grassland. I. Patterns in undisturbed vegetation. J Ecol 69:825-841.

Franke M, Morton J. 1994. Ontogenetic comparisons of arbuscular mycorrhizal fungi Scutellospora heterogama and Scutellospora pellucida: revision of taxonomic character concepts, species descriptions, and phylogenetic hypotheses. Can J Bot 72:122-134.

Gerdemann JW, Trappe JM. 1974. Endogonaceae in the Pacific Northwest. Mycol Mem 5:1-76.

Koske RE, Gemma JN. 1989. A modified procedure for staining roots to detect VA mycorrhizas. Mycol Res 92: 486-505.

— Tessier B. 1983. A convenient, permanent slide mounting medium. Newslett Mycol Soc Amer 34:59.

Janos DP, Trappe JM. 1982. Two Acaulospora species from tropical America. Mycotaxon 15:515-522.

Moloney KA. 1988. Fine-scale spatial and temporal variation in the demography of a perennial bunch grass. Ecology 69:1588-1598.

Morton J, Bentivenga S, Wheeler W. 1993. Germ plasm in the International Collection of Arbuscular and Vesicular-arbuscular Mycorrhizal Fungi (INVAM) and procedures for culture development, documentation, and storage. Mycotaxon 48:491-528.

Morton JB. 1986. Effects of mountants and fixatives on morphology and Melzer's reaction of spores of two Acaulospora species (Endogonaceae). Mycologia 78:787794.

1995. Taxonomic and phylogenetic divergence among five Scutellospora species (Glomales, Zygomycetes) based on comparative developmental sequences. Mycologia 87:127-137.

- 1996. Redescription of Glomus caledonium based on correspondence of spore morphological characters in type specimens and a living reference culture. Mycorrhiza $6: 161-166$.

—. Bentivenga SP, Bever JD. 1995. Discovery, measurement, and interpretation of diversity in symbiotic en- 
domycorrhizal fungi (Glomales, Zygomycetes). Can J Bot 73(suppl):25-32.

Schenk NC, Spain JL, Sieverding E, Howler RH. 1984. Several New and unreported vesicular-arbuscular mycorrhizal fungi (Endogonaceae) from Columbia. Mycologia 76:685-699.

Schultz P. 1996. Arbuscular mycorrhizal species diversity and distribution in an old field community [ $\mathrm{PhD}$ Thesis]. Durham, North Carolina: Duke University. $126 \mathrm{p}$.

Stürmer SL, Morton JB. 1997. Developmental patterns defining morphological characters in spores of species in Glomus (Glomales, Zygomycetes). Mycologia 89:72-81. 